\title{
PEMBENTUKAN PORTOFOLIO OPTIMAL SAHAM INDEKS LQ-45 DANJAKARTA ISLAMIC INDEX (JII)
}

\author{
Erna Retna Rahadjeng \\ Jurusan Manajemen, Universitas Muhammadiyah Malang \\ Email:erna_retna@yahoo.co.id
}

\begin{abstract}
This research is a case study conducted in EfekIndonesia Exchange under the title "Determination of Optimal Portfolio shares and shares of LQ45 JII". The purpose of this study is to identify the combination of shares and the amount of the proportion of funds that can form the optimal portfolio and to determine the level of risk and return of the optimal portfolio is formed. Sampling method in this study, namely purposive sampling. The criteria in this study is that stocks are always included in the index and the index JII LQ45 over the study period. The method used in determining the optimal portfolio is the single index model. The conclusion of this research is that there are three stocks, and four 45 LQ JII stocks that can form the optimal portfolio, which shares BNII, AALI, and UNSP for LQ 45, while for the stock is AALI JII, KLBF, TLKM, and INCO. Risk portfolio of 45 stocks LQ $1.635116 \%$ with a repayment rate of $0.639931 \%$, while the risk portfolio of stocks JII $-0.0194424 \%$ with portfolio returns of $0.191527 \%$. Thus, the purpose and formulation of the problem unanswered.
\end{abstract}

Keywords: portfolio optimal, model index tunggal, index saham LQ45, saham JII

Pasar modal merupakan pasar untuk berbagai instrument keuangan jangka panjang yang kegiatannya adalah jual beli sekuritas, baik dalam bentuk utang ataupun modal sendiri yang menjadi salah satu sumber untuk mendapatkan dana atau modal untuk pembiayaan pembangunan nasional. Adanya pasar modal sebagai salah satu pelaku ekonomi nasional memiliki fungsi intermediasi yaitu menjembatani antara pihak yang membutuhkan modal dengan pihak yang kelebihan modal, serta memperbanyak pilihan sumber dana bagi perusahaan swasta dan pemerintah. Jangkauan dan misi pasar modal di Indonesia mencakup tiga aspek mendasar yang ingin dicapai yaitu; mempercepat proses perluasan partisipasi masyarakat, pemerataan pendapatan masyarakat, menggairahkan partisipasi masyarakat dalam pengarahan dan perhimpunan dana untuk digunakan secara produktif.

Kehadiran pasar modal, juga melengkapi peranan sistem perbankan sebagai alternatif sumber pembiayaan bagi dunia usaha, terutama bagi perusahaan yang ingin melakukan ekspansi usaha dengan melakukan penawaran umum. Penawaran umum atau dikenal dengan istilah go public merupakan sebuah proses penjualan saham oleh perseroan kepada masyarakat. Perusahaan-perusahaan menarik dana masyarakat dengan menawarkan kepemilikan saham yang menyatakan satu unit kepemilikan dari perusahaan. Diketahui bahwa, saham merupakan surat berharga atau efek yang diterbitkan oleh perusahaan yang terdaftar di bursa (go public). Banyak perusahaan yang terdaftar di bursa menyebabkan banyaknya penawaran saham ke masyarakat. Hal ini memberikan banyak kebebasan pilihan bagi investor dalam menginvestasikan dananya pada saham-saham perusahaan yang terdaftar di pasar modal.

Investasi merupakan komitmen penempatan sejumlah dana pada satu atau beberapa objek investasi dengan harapan akan mendapatkan keuntungan di masa yang akan datang. Secara umum investor dapat melakukan investasi, yaitu investasi pada aset-aset finansial (financial assets) dan investasi pada asetaset riil (real assets). Investasi pada aset-aset finansial dilakukan di pasar uang dan pasar modal. Investasi di pasar uang dapat berupa sertifikat deposito, commercial paper, surat berharga pasar uang, dan lain-lain. Investasi dapat juga dilakukan di pasar modal, misalnya berupa saham, obligasi, warant, opsi, dan lain-lain. Investasi pada aset-aset riil dapat berupa pembelian terhadap aset-aset produktif, pendirian pabrik, pembukaan perkebunan, pembukaan pertambangan, dan lain sebagainya (Halim, 2005). 
Semua investasi mengandung unsur ketidakpastian atau risiko, sehingga investor tidak mengetahui secara pasti hasil yang akan diperoleh dari investasi yang dilakukannya. Adanya keadaan seperti itu, maka seorang investor harus memperkirakan berapa keuntungan yang diharapkan dari investasinya dan seberapa jauh kemungkinan tingkat keuntungan yang akan diperoleh menyimpang dari tingkat keuntungan yang diharapkan. Para investor sebelum mengambil keputusan menginvestasikan dananya pada saham, harus mengetahui bahwa saham merupakan instrumen yang mempunyai karakteristik high risk-high return, artinya akan memperoleh peluang keuntungan tinggi, namun juga akan berpotensi menghadapi risiko tinggi.

Investasi pada saham mempunyai keunggulan, yaitu akan memperoleh return yang berasal dari capital gain dan deviden. Deviden yang diperoleh oleh seorang investor ditentukan oleh kemampuan perusahaan dalam memperoleh laba. Return yang berasal dari capital gain yang diperoleh, juga dipengaruhi oleh fluktuasi harga saham. Kemampuan perusahaan memperoleh laba dipengaruhi oleh faktor mikro dan makro yang pada gilirannya akan berpengaruh terhadap fluktuasi harga saham. Kedua faktor tersebut akan mempengaruhi risiko investasi saham.

Pada umumnya para investor mengelola risiko ketidakpastian dalam berinvestasi pada saham dapat melakukan prinsip diversifikasi. Prinsip diversifikasi merupakan penyebaran risiko karena ada unsur ketidakpastian, dengan melakukan investasi lebih dari satu jenis saham. Dalam bahasa klasik, menempatkan telur di beberapa keranjang. Bila satu keranjang telur dijual dengan harga murah, maka telur dalam keranjang lain dijual mahal. Kerugian di satu keranjang di kompensasi dengan keuntungan dari keranjang lain. Keuntungan dan kerugian yang saling menutupi ini menurunkan risiko. Salah satu strategi yang dapat digunakan untuk menerapkan prinsip diversifikasi dalam berinvestasi pada saham yang penuh risiko, dengan mengunakan analisis portofolio.

Risiko dalam konteks portofolio dapat dibedakan menjadi dua, yaitu risiko sistematis dan risiko tidak sistematis. Risiko sistematis merupakan risiko yang tidak dapat dihilangkan atau dibatasi dengan melakukan diversifikasi, karena fluktuasi risiko ini dipengaruhi oleh faktor-faktor makro yang dapat mempengaruhi semua saham secara keseluruhan dalam pasar modal, misalnya; risiko inflasi, risiko perubahan tingkat suku bunga, risiko pasar, dan sebagainya. Risiko tidak sistematis merupakan risiko yang dapat dihilangkan meliputi; risiko likuiditas, risiko perubahan kurs valuta asing, risiko utang, dan sebagainya. Risiko tidak sistematis tidak mempengaruhi keseluruhan saham emiten, hanya terjadi pada saham tertentu yang dapat dihilangkan dengan melakukan diversifikasi, sehingga tujuan pembentukan portofolio adalah untuk meminimalkan risiko dan memperoleh hasil yang optimal.

Portofolio merupakan kumpulan aset-aset yang menjadi pilihan seorang investor. Pembentukan portofolio adalah untuk mengurangi risiko dengan cara diversifikasi investasi, yaitu mengalokasikan sejumlah dana pada berbagai alternatif investasi yang berkorelasi negatif. Investor mengkombinasikan berbagai saham dalam investasinya untuk mengoptimalkan return dan diharapkan bisa meminimalkan tingkat risiko yang dimiliki oleh masing-masing saham yang membentuk portofolio itu.

Portofolio optimal dapat digunakan investor untuk mengambil keputusan investasinya. Sebelum menentukan portofolio optimal harus melakukan pemilihan portofolio yang efisien. Semua portofolio optimal merupakan portofolio yang efisien, di mana portofolio optimal dapat ditentukan dengan model indeks tunggal dan indeks ganda yang sesuai dengan preferensi investor yang bersangkutan terhadap tingkat pengembalian, maupun risiko yang bersedia ditanggungnya.

Model indeks tunggal (Single Index Models) dikembangkan oleh William Sharpe guna menyederhanakan perhitungan di Model Markowitz. Model indeks tunggal mendasarkan diri atas pemikiran, bahwa tingkat keuntungan suatu saham dipengaruhi oleh tingkat keuntungan pasar di mana tingkat pengembalian antara dua efek atau lebih mempunyai kolerasi, yaitu akan bergerak bersama dan mempunyai reaksi yang sama terhadap satu faktor atau indeks tunggal yang dimasukkan dalam model (Halim, 2005:82). Faktor atau indeks tersebut adalah Indeks Harga Saham Gabungan (IHSG). Indeks harga saham gabungan (indeks pasar) sebagai faktor makro umum. Model indeks tunggal menjadi penting untuk membantu spesialisasi analisis sekuritas, pengunaan model indeks tunggal juga sangat populer, dan banyak digunakan untuk melakukan analisis portofolio optimal dalam menghitung tingkat pengembalian efek (expected return) dan risiko portofolio. Model indeks tunggal masih sesuai dengan konsep portofolio faktor.

Penyederhanaan yang diturunkan dari asumsi models indeks tunggal bukan tanpa biaya. "Biaya" model ini terletak pada ketidakpastian struktur imbal hasil pasar. Klasifikasi ketidakpastian ke dalam dikotomi risiko mikro vs makro terlalu menyederhanakan sumber ketidakpastian dalam dunia nyata dan 
menyebabkan hilangnya faktor peristiwa-peristiwa indukstri, peristiwa-peristiwa yang mungkin memengaruhi sejumlah perusahaan di dalam suatu industri tanpa banyak mempengaruhi sejumlah perusahaan.

Penentuan portofolio optimal dengan model indeks ganda (multiple indeks models) atau dikenal dengan sebutan model multifaktor, dikembangkan untuk meningkatkan kemampuan penjelas dari model indeks tunggal dengan secara eksplisit memperhitungkan berbagai komponen sistematis dari risiko sekuritas. Model ini menggunakan indikator yang ditujukan untuk dapat merangkum sejumlah besar faktor risiko ekonomi makro, sehingga model multifaktor tidak lebih sebuah penjelasan faktor yang mempengaruhi imbal hasil saham. Model ini mengasumsikan ada banyak faktor yang mempengaruhi return sekuritas selain indeks harga saham gabungan, misalnya faktor tingkat bunga bebas risiko, inflasi, dan lain sebagainya.

Adanya model multifaktor, masih mempunyai kelemahan di mana belum sesuai dengan konsep portofolio faktor (faktor portofolio). Portofolio faktor yang merupakan portofolio yang terdiversifikasi dengan baik yang dibentuk untuk mempunyai beta sebesar 1 pada satu faktor dan beta sebesar 0 untuk faktor lain (Bodie, dkk., 2006). Investor dapat melihat portofolio faktor sebagai portofolio tracking. Artinya, imbal hasil portofolio tersebut melacak evolusi sumber risiko ekonomi makro tertentu tetapi tidak berkorelasi dengan sumber risiko yang lain. Penerapan model indeks ganda akan dipengaruhi oleh penilaian analisis dalam memilih faktor-faktor yang diduga dapat mempengaruhi tingkat pengembalian suatu efek dan risikonya. Selain itu, teori model indeks ganda tidak banyak memberikan panduan tentang bagaimana menentukan faktor risiko yang relevan maupun premi risiko atas setiap sumber faktor tersebut.

Bursa efek merupakan suatu sistem yang terorganisasi dengan mekanisme resmi untuk mempertemukan penjual dan pembeli efek secara langsung atau melalui wakil-wakilnya. Bursa Efek Jakarta (BEJ) sebagai salah satu bursa saham yang dapat memberikan peluang investasi dan sumber pembiayaan dalam upaya mendukung pembangunan ekonomi nasional. Pasar Modal Indonesia berperan dalam mengembangkan pemodal lokal yang jumlahnya besar dan solid untuk menciptakan pasar modal Indonesia yang stabil. Sistem perdagangan sejak tanggal $22 \mathrm{Mei}$ 1995 di BEJ menggunakan sistem komputerisasi yang dikenal dengan nama JATS (Jakarta Automated Trading System), menggantikan sistem manual dalam menciptakan perdagangan yang transparan, efisien, dan pasar yang efektif bagi para investor. Perdagangan di BEJ didasarkan pada sistem order (order driven market system) dan sistem lelang kontinyu (continous auction system). Sistem order, investor harus menghubungi perusahaan sekuritas yang kemudian menjalankan ordernya. Sistem lelang kontinyu, maksudnya harga transaksi ditentukan oleh penawaran dan permintaan yang dilaksanakan secara berkesinambungan selama jam perdagangan.

Indeks harga saham merupakan indikator harga dari seluruh saham yang tercatat di bursa efek. Indikator utama pergerakan harga saham di Bursa Efek Jakarta merupakan Indeks Harga Saham Gabungan (IHSG) yang diperkenalkan pada tanggal 1 April 1983. Indeks ini, mencakup pergerakan harga seluruh saham biasa dan saham preferen yang tercatat di BEJ. Pertumbuhan IHSG menunjukkan trend yang terus meningkat, dibandingkan dengan indeks utama dari beberapa bursa efek di kawasan Asia Pasifik, IHSG BEJ merupakan satu indeks yang kinerjanya terbaik ke-3 sepanjang tahun 2006 .

Adapun tujuan penelitian adalah untuk mengetahui kombinasi saham-saham dan jumlah proporsi dana yang dapat membentuk portofolio optimal pada saham LQ45, mengetahui kombinasi saham-saham dan jumlah proporsi dana yang dapat membentuk portofolio optimal baik pada saham JII, mengetahui tingkat risiko dan pengembalian dari portofolio optimal yang terbentuk, serta mengetahui persamaan saham-saham yang terbentuk pada saham LQ45 juga terbentuk pada saham JII.

\section{METODE}

Penelitian yang dilakukan penulis merupakan penelitian studi kasus (case study), di mana peneliti menggali suatu fenomena tertentu dengan mengkaji objek tertentu, sehingga hasil penelitian hanya dapat diimplementasikan pada objek penelitian saja dan bertujuan untuk mengambarkan secara tepat dan sistematis terhadap fenomena-fenomena yang diteliti. Pemilihan jenis penelitian ini sesuai dengan tujuan penelitian, yaitu: untuk mengetahui kombinasi sahamsaham dan proporsi dana yang dapat membentuk portofolio optimal, serta tingkat risiko dan pengembalian dari portofolio optimal.

Setelah data untuk penelitian diperoleh selanjutnya dilakukan analisis data supaya dapat ditentukan portofolio optimal. Langkah-langkah untuk penentuan portofolio saham optimal dengan model indeks tunggal adalah sebagai berikut: (1) Menghitung nilai ERB dan 
mengurutkan peringkat saham yang tertinggi hingga terendah terhadap ERB (excess return to beta) yang positif. (2) Menghitung nilai $A_{i}$ dan $B_{i}$ untuk masingmasing sekuritas. (3) Menentukan cut off Rate (Ci) untuk sekuritas. (4) Menentukan cut off point $\mathrm{C}^{*}$ yang merupakan nilai $\mathrm{Ci}$ di mana nilai ERB terakhir kali masih lebih besar dari nilai $\mathrm{Ci}$ dan selanjutnya menentukan kombinasi saham-saham yang membentuk portofolio optimal dari saham-saham yang mempunyai nilai ERB lebih besar atau sama dengan nilai ERB di titik $C^{*}$. (5) Menentukan proporsi masingmasing sekuritas dalam portofolio optimal dihitung dengan Wi. (6) Menentukan tingkat pengembalian dan risiko dari portofolio optimal.

\section{HASIL DAN PEMBAHASAN}

Penelitian ini menggunakan model indeks tunggal dalam pembentukan portofolio optimal pada saham LQ 45 dan JII. Dalam pembentukan portofolio, para investor berusaha untuk memaksimumkan tingkat pengembalian yang diharapkan dari investasi tertentu dengan tingkat risiko yang dapat diterima atau dengan risiko yang terendah untuk memperoleh tingkat pengembalian tertentu. Portofolio yang memenuhi dan memuaskan persyaratan ini disebut portofolio yang efisien, diasumsikan bahwa para investor dalam pembuatan keputusan investasi berperilaku sebagai penghindar risiko.

Mengurutkan saham-saham berdasarkan nilai excess return to beta terbesar ke nilai yang terkecil dengan return aktiva bebas risiko sebesar $8,61 \%$. Saham-saham dengan nilai excess return to Beta yang terbesar merupakan kandidat untuk dimasukkan ke portofolio yang optimal. Hasil penghitungan ERBi dapat diketahui saham yang memiliki ERBi tertinggi yaitu AALI sebesar -0,349990456\% dan nilai ERBi yang terendah yaitu UNVR sebesar -2,576996396. Dari perhitungan ini maka investor yang rasional akan cenderung memilih ERBi yang tertinggi yaitu AALI. Portofolio yang optimal akan berisi dengan sahamsaham yang mempunyai nilai rasio excess return to beta yang tinggi. Saham-saham dengan rasio excess return to beta yang rendah tidak akan dimasukkan ke dalam portofolio yang optimal. Dengan demikian diperlukan sebuah titik pembatas (cut-off point) yang menentukan batas nilai excess return to Beta berapa yang dikatakan tinggi.

Setelah ditentukannya nilai ERBi, untuk membentuk portofolio optimal langkah berikutnya adalah dengan menentukan besarnya cut-off point $\left(\mathrm{C}^{*}\right)$.
Besarnya cut-off point adalah nilai $\mathrm{C}_{\mathrm{i}}$ di mana nilai ERBi terakhir kali masih lebih besar dari nilai $C_{i}$. Sekuritas-sekuritas yang membentuk portofolio optimal adalah sekuritas-sekuritas yang mempunyai nilai ERBi lebih besar atau sama dengan nilai ERBi di titik $C^{*}$. Sekuritas-sekuritas yang mempunyai ERB lebih kecil dengan ERBi di titik $C^{*}$ tidak dimasukkan dalam pembentukan portofolio optimal.

NilaiC" terbesar untuk saham JII adalah $-0,90184488$ yaitu PT INCO, sedangkan untuk sekuritas PT. PT. Astra Agro Lestari,Tbk (AALI) dengan nilai ERBI sebesar -0,349990456 sudah lebih besar dari nilai Ci yaitu sebesar -0,55551989. Nilai ERBi selanjutnya, yaitu PT KalbeFarma,Tbk(KLBF) sebesar-0,361874346 sudah lebih besar dari nilai Ci yaitu sebesar -0,75890107. Nilai ERBi yang ketiga PT Telekomunikasi Indonesia, Tbk (TLKM) sebesar -0,381747455 lebih besar dari $\mathrm{C}_{\mathrm{i}}$ yaitu sebesar $-0,76964811$, dan yang terakhir PT INCO memiliki nilai ERBi sebesar-0,412925034 masih lebihbesar dari pada nilai C sebesar $-0,90184488$. Besarnya proporsi dana dalam portofolio optimal sebagai berikut: (1) Saham AALI. dengan return ekspektasi sebesar $0,593027 \%$ dan total risiko sebesar $-0,00672 \%$ masuk ke dalam portofolio optimal dengan proporsi dana sebesar 55,0971\%; (2) Saham KLBF Tbk. dengan return ekspektasi sebesar $-0,7475 \%$ dan total risiko sebesar $-0,0028 \%$, masuk ke dalam portofolio optimal dengan proporsi dana sebesar $6,875 \%$; (3) Saham TLKM dengan return ekspektasi sebesar $-0,06602 \%$ dan total risiko sebesar $-0,00205 \%$, masuk ke dalam portofolio optimal dengan proporsi dana sebesar 23,9384\%. Dan (4) Saham INCO. dengan return ekspektasi sebesar - $0,4621 \%$ dan total risiko sebesar $-0,00788 \%$, masuk ke dalam portofolio optimal dengan proporsi dana sebesar 14,0896\%.

Mengurutkan saham-saham LQ 45 berdasarkan nilai excess return to Beta terbesar ke nilai yang terkecil dengan return aktiva bebas risiko sebesar $8,61 \%$. Saham-saham dengan nilai excess return to beta yang terbesar merupakan kandidat untuk dimasukkan ke portofolio yang optimal. Hasil penghitungan ERBi dapat diketahui saham yang memiliki ERBi tertinggi yaitu BNII sebesar 3,367945\% dan nilai ERBi yang terendah yaitu ISAT sebesar $-1,64846 \%$. Dari perhitungan ini maka investor yang rasional akan cenderung memilih ERBi yang tertinggi yaitu BNII.

Portofolio yang optimal akan berisi dengan sahamsaham yang mempunyai nilai rasio excess return to beta yang tinggi. Saham-saham dengan rasio excess return to beta yang rendah tidak akan dimasukkan ke dalam portofolio yang optimal. Dengan demikian 
diperlukan sebuah titik pembatas (cut-off point) yang menentukan batas nilai excess return to Beta berapa yang dikatakan tinggi. Langkah berikutnya adalah Menentukan besarnya cut-off point $\left(\mathrm{C}^{*}\right)$. Besarnya cut-off point adalah nilai $\mathrm{C}_{\mathrm{i}}$ di mana nilai ERBi terakhir kali masih lebih besar dari nilai $\mathrm{C}_{i}$. Sekuritassekuritas yang membentuk portofolio optimal adalah sekuritas-sekuritas yang mempunyai nilai ERBi lebih besar atau sama dengan nilai ERBi di titik $C^{*}$. Sekuritas-sekuritas yang mempunyai ERB lebih kecil dengan ERBi di titik $C^{*}$ tidak dimasukkan dalam pembentukan portofolio optimal. Nilai C* terbesar -1,61429 untuk sekuritas PT Bakrie Sumatra Plantation,Tbk dan PT. Bank Internasional Indonesia,Tbk (BNII) dengan nilai ERB sebesar 3,367945 yang merupakan nilai ERBi terbesar dari nilai Ci. Nilai ERBi PT. Astra Agro Lestari, Tbk (AALI) sebesar -0,47631 juga lebih besar dari nilai Ci yaitu sebesar -3,95729. Nilai ERBi yang ketiga PT Bakrie Sumatra Plantations,Tbk (UNSP) sebesar -0,49199 lebih besar dari $\mathrm{C}_{\mathrm{i}}$ yaitu sebesar -1,61429.

Proporsi dana masing-masing sekuritas bila dihubungkan dengan nilai return ekspektasi dan total risiko. Besarnya proporsi dana dalam portofolio optimal sebagai berikut: (a) Saham BNII. dengan return ekspektasi sebesar 0,594690325\% dan total risiko sebesar $0,001512 \%$ masuk ke dalam portofolio optimal dengan proporsi dana sebesar $6,1401 \%$; (b) Saham AALI Tbk. dengan return ekspektasi sebesar $0,712202991 \%$ dan total risiko sebesar $-0,01128 \%$, masuk ke dalam portofolio optimal dengan proporsi dana sebesar 86,4047\%; dan (c) Saham UNSP. dengan return ekspektasi sebesar $-0,138652864 \%$ dan total risiko sebesar $-0,00367 \%$, masuk ke dalam portofolio optimal dengan proporsi dana sebesar 7,5441\%.

Hasil analisa data selama periode pengamatan yaitu pada Januari 2007-Januari 2009 untuk indeks LQ 45 ada 26 emiten yang dijadikan sampel dan untuk indeks JII ada 11 emiten yang dijadikan sampel dalam penelitian saat ini, dan menghasilkan portofolio optimal untuk saham LQ 45 ada (tiga) 3 saham yang terbentuk, sedangkan untuk indeks JII yang terbentuk dalam portofolio optimal ada empat (4) saham. Saham-saham tersebut antara lain: BNII dengan proporsi dana $6,1401 \%$, AALI 86,4047\% dan UNSP 7,6441\% untuk saham LQ 45, sedangkan untuk saham JII yang terbentuk adalah AALI dengan proporsi dana 55,0971\%, KLBF 6,875\%, TLKM 23,9384\% dan INCO sebesar $14,0896 \%$.
Saham yang masuk dalam portofolio optimal ini memiliki return portofolio sebesar 0,6399315 dengan tingkat risiko portofolio sebesar 1,635116 untuk saham LQ 45, sedangkan return portofolio optimal saham JII sebesar 0,191527\% dengan tingkat risiko portofolio sebesar -0,0194424\%. Berdasarkan hasil analisis data menerangkan bahwa pembentukan portofolio optimal saham LQ 45 dan saham JII tidak memiliki kesamaan saham yang terbentuk, hanya saham AALI yang mewakili kedua indeks tersebut.

\section{KESIMPULAN DAN SARAN}

\section{Kesimpulan}

Setelah dianalisis dan diperhitungkan maka dapat disimpulkan bahwa saham yang terbentuk pada portofolio optimal untuk saham LQ 45 hanya (tiga) 3 saham dari 26 emiten yang dijadikan sampel, sedangkan untuk indeks JII hanya (empat) 4 saham dari 11 emiten yang terbentuk portofolio optimal. Berdasarkan perhitungan dan penentuan portofolio optimal saham LQ 45 dan saham JII menunjukkan bahwa tidak semua saham terbentuk secara bersama-sama baik pada indeks JII maupun indeks LQ 45, hal ini dikarenakan adanya perbedaan penentuan RBR. Untuk LQ 45 menggunakan RBR yang didasarkan pada BI sedangkan indeks JII nilai RBR nya menggunakan SWBI. Berdasarkan hasil analisis data maka untuk rumusan yang keempat tidak terbukti, hal ini menunjukkan bahwa sebagian sahamyang ada di dalam indeks JII dan Indeks LQ 45 memiliki karakteristik yang berbeda untuk dijadikan investasi.

\section{Saran}

Berdasarkan kesimpulan di atas, ada beberapa saran yang diharapkan dapat dijadikan bahan pertimbangan dalam melakukan investasi; bagi Investor apabila ingin menanamkan investasi pada saham seharusnya membentuk portofolio optimal seperti ini. Dengan terbentuknya portofolio optimal akan membantu para investor didalam mendapatkan return tertinggi dengan risiko tertentu atau dengan risiko terendah akan mendapatkan return tertentu Sedangkan bagi peneliti selanjutnya, disarankan jika akan melakukan penelitian yang serupa agar memperhatikan dengan baik dalam melakukan analisis pembentukan portofolio optimal, agar hasil yang diperoleh bisa lebih akurat, dan sebaiknya bisa melakukan analisis dalam satu periode saja agar mendapatkan kombinasi saham yang lebih akurat. 


\section{DAFTAR RUJUKAN}

Chimky. 2008. Pembentukan Portofolio Optimal dengan Menggunakan Indeks Tunggal (Studi Pada sahamSaham JII Periode 2004-2006), Skripsi, UMM.

Darmadji dan Hendy, M.F. 2006. Pasar Modal di Indonesia; Edisi 2. Jakarta: Salemba Empat.

Fakhruddin dan Sopian, H. 2001. Perangkat dan Model Analisis Investasi di Pasar Modal. Jakarta: Buku Satu, Elex Media Komputindo.

Halim, A. 2002. Analisis Investasi. Jakarta: Salemba Empat.

Husnan, S. 2001.Dasar-Dasar Teori Portofolio dan Analisis Sekuritas, Edisi ketiga. Yogyakarta: AMP YPKAN.

Jogiyanto. 2000, Teori Portofolio dan Analisis Investasi; Edisi 2. Yogyakarta: BPFE.

Kuncoro, M. 2003. Metode Riset untuk Bisnis dan Ekonomi. Jakarta: Erlangga.

Rahmat, P.A. 2006. "Analisis dan Seleksi Saham dalam Rangka Pembentukan dan Pemilihan Portofolio
Saham yang Optimal pada Saham-Saham LQ45 Yang Listing di BEJ'. Skripsi UMM.

Rianse, U., dan Abdi. 2008. Metodologi Penelitian Sosial dan Ekonomi Teori dan Aplkasi; Edisi Pertama. Bandung: Alfabeta.

Sigit, S. 2001. Pengantar Metodologi Penelitian SosialBisnis-Manajemen. Yogyakarta: BPFE UST.

Sunariyah. 1997. Pengantar Pengetahuan Pasar Modal. Yogyakarta: Unit Penerbit dan Percetakan AMP YKPN.

Tandelilin, E. 2001. Analisis Investasi dan Manajemen Portofolio; Edisi Pertama. Yogyakarta: BPFE.

Wahyuni. 2006. Penerapan Model Indeks Tunggal untuk Membentuk Portofolio Optimal dalam Pengambilan Keputusan Investasi Saham (Studi pada saham Indeks LQ-45 di Bursa Efek Jakarta Periode Agustus 2004-Juli 2005), Skripsi, UMM.

Widoatmojo, S. 1996. Cara Sehat Investasi di Pasar Modal. Jakarta: PT Jurnalindo Aksara Grafika. 